\title{
Selectivity analysis of protein kinase CK2 inhibitors DMAT, TBB and resorufin in cisplatin-induced stress responses
}

\author{
GERHARD FRITZ ${ }^{1}$, OLAF-GEORG ISSINGER ${ }^{2}$ and BIRGITTE BRINKMANN OLSEN ${ }^{2}$ \\ ${ }^{1}$ Department of Toxicology, University of Mainz, D-55131 Mainz, Germany; ${ }^{2}$ Institute of Biochemistry \\ and Molecular Biology, University of Southern Denmark, DK-5230 Odense, Denmark
}

Received May 13, 2009; Accepted June 23, 2009

DOI: 10.3892/ijo_00000431

\begin{abstract}
Targeting protein kinases as a therapeutic approach to treat various diseases, especially cancer is currently a fast growing business. Although many inhibitors are available, exhibiting remarkable potency, the major challenge is their selectivity. Here we show that the protein kinase CK2 inhibitors DMAT, TBB and resorufin differ in their selectivity against PI3K family members, since PI3K and DNAPK are subject to inhibition by DMAT and TBB, however, not by resorufin. TBB and DMAT treatment together with cisplatin lead to an inhibition of cisplatin-induced stress signaling (as detected by phosphorylation of JNK and H2AX). In the case of resorufin no interference with the stresssignaling pathway is observed, supporting the notion that TBB and DMAT interfere with upstream molecules involved in genotoxic stress signaling. We have also tested the protein kinase CK2 inhibitors with respect to cell viability and inhibition of endogenous CK2 activity in the absence and presence of the anti-cancer drug cisplatin. The strongest effect on viability was observed with resorufin. In contrast to resorufin, TBB protected cells from cisplatin-induced cell killing. Furthermore, the inhibition of endogenous CK2 activity was cell type-dependent as endogenous CK2 was inhibited to different degrees in the cell lines.
\end{abstract}

\section{Introduction}

Protein kinase CK2 is a ubiquitous, pleiotropic serine/threonine protein kinase distantly related to the CMGC subfamily of protein kinases. The heterotetrameric holoenzyme consists of two catalytic $\alpha$-subunits and a non-catalytical dimer $\left(\beta_{2}\right)$. The structure of the CK2 subunits and of the tetrameric holoenzyme have been solved (1-5) supporting previous biochemi-

Correspondence to: Dr Birgitte Brinkmann Olsen, BMB, University of Southern Denmark, Campusvej 55, 5230 Odense, Denmark

E-mail: bbo@bmb.sdu.dk

Key words: DNA-PK, protein kinase inhibitors, CK2, stress kinases, cisplatin cal data that this enzyme is, unlike most other protein kinases, not regulated by phosphorylation, second messengers or activating molecules such as cyclins as in the case of CDKs, and is believed to be constitutively active (6). Another peculiar characteristic of CK2 is its capability to use ATP and GTP as phosphoryl donors (7). It is now common belief that CK2 exhibits anti-apoptotic properties and that down-regulation of the enzyme activity favors programmed cell death (8).

Beside the CK2 $\alpha$-subunit, which has been described in most cells and tissues, an isozyme, i.e., CK $2 \alpha^{\prime}$ has been found to be predominantly expressed in brain and testes (9). Knockout experiments of protein kinase CK2 $\alpha$ and $\beta$-subunits were lethal in early embryonic stage of mouse development $(10,11)$, whereas the knockout of CK2 $\alpha^{\prime}$ led to a phenotype resembling globozoospermia in man (12), supporting the notion that the major CK2 subunits, i.e. $\alpha$ and $\beta$ are essential for life.

Although it is the heterotetrameric holoenzyme that has been predominantly found and described, there are also reports suggesting the presence of free CK2 subunits or in association with various other proteins (reviewed in refs. 13-15). Moreover, protein kinase CK2 has been shown to be associated with many different diseases, especially cancer (16). Hence, it is not surprising that CK2 has become a 'druggable' kinase $(6,17,18)$ and intensive efforts have been made in search for potent and specific small molecule inhibitors. Six major classes of ATP-site directed CK2 inhibitors (type I inhibitors) have been described (18-22): i) flavonoids (apigenin and quercetin), ii) hydroxyanthraquinones/xanthenones/hydroxycoumarines [emodin, 1,8dihydroxy-4-nitroxanthen-9-one (MNX), 3,8-dibromo-7hydroxy-4-methylchromen-2-one (DBC), 8-hydroxy-4methyl-9-nitrobenzo(g)chromen-2-one (NBC)], iii) halogenated (aza)imidazoles [5,6-dichloro-1(ß-D-ribofuranosyl)benzimidazole (DRB), 4,5,6,7-tetrabromobenzotriazole (TBB), 2-dimethylamino-4,5,6,7-tetrabromo-1H-benzimidazole (DMAT), tetrabromocinnamic acid (TBCA)], iv) indolo quinazolines [(5-oxo-5,6-dihydroindolo-(1,2-a)quinazolin-7yl)acetic acid (IQA)], v) pyraxolo(1,5-a)triazines and vi) carboxamides/carboxylic acids.

Among the most popular CK2 inhibitors are currently TBB and DMAT. Although both compounds exhibit a remarkable potency with respect to CK2 inhibition (23-25) their selectivity for CK2 is not optimal (26). Recently, a new and highly selective CK2 inhibitor resorufin was described (27). In 
contrast to the so far described CK2 inhibitors, resorufin is characterized by an exceptionally high degree of selectivity. The $K_{i}$ values were determined for the holoenzyme and the free catalytic subunit to be 0.8 and $1.3 \mu \mathrm{M}$, respectively, which compares well with the best described CK2 inhibitors. Out of 52 kinases tested, only CK2 was inhibited by resorufin. In contrast, the most popular CK2 inhibitors, i.e., TBB and DMAT, also inhibited protein kinases DYRK1a, HIPK2, PIM2, PIM3 and PKD1 $(26,27)$.

There is a controversy concerning the strategy of inhibition with respect to therapeutically rationale approaches, i.e., to focus on one kinase only, e.g., EGFR (Gefinitib), or rather to focus on multi-targets such as RAF kinase and VEGF (Sorafinib, Sutent) (28). However, irrespective which strategy is used, the compounds used should exhibit a high degree of selectivity towards the targets chosen.

The present investigations, where TBB, DMAT and resorufin were used in two different tumor cell lines in the absence and presence of the anti-cancer drug cisplatin, show that the lack of selectivity (as observed with TBB and DMAT) may interfere with major signaling pathways including PI3K (phosphoinositide-3 kinase) and DNA-PK (DNA-dependent protein kinase) regulated mechanisms.

\section{Materials and methods}

Materials. The anti-cancer drug cisplatin was obtained from Sigma-Aldrich (Taufkirchen, Germany). Phosphospecific antibodies p-JNK (p-T183/p-Y185) and p-p38 (p-T180/pY182) were from New England Biolabs GmbH (Frankfurt, Germany). The antibody detecting phosphorylated histone H2AX (p-S139) ( $\gamma$-H2AX) was from Upstate (Hamburg, Germany) and ERK2 specific antibody was purchased from Santa Cruz Biotechnology Inc. (Santa Cruz, CA, USA).

CK2 inhibitors TBB and DMAT were obtained from EMD (Nottingham, UK). Resorufin and the CK2 synthetic peptide (RRRADDSDDDDD) were from KinaseDetect ApS (Odense, Denmark). The synthetic peptide for DNA-PK (PESQEAFADLWKK) was from EZ Biolabs (Westfield, IN, USA) and $\left[\gamma^{-32} \mathrm{P}\right]$-ATP $(3,000 \mathrm{Ci} / \mathrm{mmol})$ was obtained from Hartmann Analytic (Braunschweig, Germany).

Luminometric determination of PI3K activity. Determination of PI3K activity was performed by a luminometric approach as previously described (29) using $10 \mu \mathrm{M}$ of inhibitor. Activity was calculated as the reduction in luminescence relative to samples without PI3K.

Cell culture and viability assay. Human breast adenocarcinoma cells MDA-MB-231 and human colorectal adenocarcinoma HT29 cells were grown in RPMI medium containing $10 \%$ fetal calf serum (Invitrogen, Carlsbad, CA, USA) at $37^{\circ} \mathrm{C}$ in an atmosphere containing $7 \% \mathrm{CO}_{2}$. Cell viability was determined by use of the colorimetric WST assay (Roche Diagnostics, Mannheim, Germany). Treatment with CK2 inhibitors was performed $24 \mathrm{~h}$ after seeding of the cells into 96-well tissue culture plates $\left(2.5 \times 10^{3}\right.$ cells/plate). After further incubation for $72 \mathrm{~h}$, cell viability was analyzed by assaying the cleavage of the tetrazolium salt WST to formazan according to the manufacturers protocol. Relative viability in untreated controls was set to $100 \%$. For Western blot analysis and protein kinase tests, cells were incubated for $16 \mathrm{~h}$ with $50 \mu \mathrm{M}$ TBB, resorufin or $25 \mu \mathrm{M}$ DMAT before addition of $50 \mu \mathrm{M}$ cisplatin for an additional $8 \mathrm{~h}$.

Western blotting. Activation of stress kinases by phosphorylation was measured by Western blot analysis using phosphospecific antibodies, which detect the dual phosphorylated (i.e. activated) form of JNK (T183/Y185) and p38 kinase (T180/Y182). Phosphorylated histone H2AX ( $\gamma$-H2AX) was also assayed by Western blot using an S139 phosphospecific antibody. Cell extracts were prepared by lysing an identical number of cells in boiling SDS sample buffer. Proteins (20-30 $\mu \mathrm{g}$ ) were separated by SDS gel electrophoresis and transferred onto nitrocellulose membrane. Subsequently, phosphorylated kinases and $\gamma-\mathrm{H} 2 \mathrm{AX}$ were visualized by chemiluminescence using ECL ${ }^{\mathrm{TM}}$ detection reagent (GE Healthcare, Munich, Germany).

Radioactive kinase activity test. For measurements of protein kinase CK2 activity, cells were washed extensively in PBS, collected by centrifugation and resuspended in cold lysis buffer $(50 \mathrm{mM}$ Tris- $\mathrm{HCl} \mathrm{pH} 7.5,150 \mathrm{mM} \mathrm{NaCl}, 1 \%$ Triton $\mathrm{X}-100,10 \%$ glycerol, $1 \mathrm{mM}$ DTT, $30 \mathrm{mM} \mathrm{Na}_{4} \mathrm{PP}_{\mathrm{i}}, 10 \mathrm{mM}$ $\mathrm{NaF}$ ) containing a protease inhibitor cocktail (Roche). Lysates were cleared by centrifugation at $4^{\circ} \mathrm{C}$ for $20 \mathrm{~min}$ at $13,000 \mathrm{x} \mathrm{g}$. Protein kinase CK2 activity test was performed for $10 \mathrm{~min}$ at $30^{\circ} \mathrm{C}$ in a total volume of $50 \mu \mathrm{l}$ containing $25 \mathrm{mM}$ Tris $-\mathrm{HCl}$ $\mathrm{pH} 8.5,150 \mathrm{mM} \mathrm{NaCl}, 5 \mathrm{mM} \mathrm{MgCl}{ }_{2}, 1 \mathrm{mM}$ DTT, $125 \mu \mathrm{M}$ ATP and $0.6 \mu \mathrm{Ci}\left[\gamma^{-32} \mathrm{P}\right]-\mathrm{ATP}(3000 \mathrm{Ci} / \mathrm{mmol}), 200 \mu \mathrm{M} \mathrm{CK} 2$ peptide and $5 \mu \mathrm{g}$ protein extract. Samples were spotted onto P81 phosphocellulose paper and washed extensively in $0.85 \mathrm{mM}$ phosphoric acid. Incorporation of radiolabeled phosphate was measured by counting samples in a liquid scintillation counter (Canberra-Packard, Downers Grove, IL, USA).

DNA-PK activity was measured in a high-salt extract prepared as previously described (30). Extract $(7 \mu \mathrm{g})$ was incubated for $5 \mathrm{~min}$ at $30^{\circ} \mathrm{C}$ in a total volume of $20 \mu \mathrm{l}$ containing $25 \mathrm{mM}$ HEPES pH 7.5, $25 \mathrm{mM} \mathrm{KCl,} 50 \mathrm{mM} \mathrm{NaCl}, 10 \mathrm{mM}$ $\mathrm{MgCl}_{2}, 0.2 \mathrm{mM}$ EDTA, $1 \mathrm{mM}$ DTT, $0.01 \mathrm{mg} / \mathrm{ml}$ sonicated salmon sperm DNA, $125 \mu \mathrm{M}$ ATP and $1 \mu \mathrm{Ci}\left[\gamma^{32} \mathrm{P}\right]-\mathrm{ATP}$ $(3000 \mathrm{Ci} / \mathrm{mmol})$ and $250 \mu \mathrm{M}$ DNA-PK peptide. Reactions were stopped by the addition of $20 \mu 1$ stop solution (30\% acetic acid, $5 \mathrm{mM}$ ATP). Samples were spotted onto P81 paper and washed extensively in $15 \%$ acetic acid before liquid scintillation counting. For measurements of DNA-PK activity in lysates the reactions contained increasing amounts of DMAT, TBB or resorufin.

\section{Results}

$T B B$ and DMAT inhibit PIBK and DNA-PK activity. Since both the protein kinase CK2 inhibitors TBB and DMAT, in contrast to resorufin, also inhibit other protein kinases $(26,27)$ we initially tested the inhibition of the recombinant PI3K $\alpha$-subunit (Fig. 1A). Indeed we showed that TBB and DMAT inhibited PI3K activity by 70 and $40 \%$, respectively. Resorufin did not show any inhibitory influence on PI3K activity (Fig. 1A) supporting the notion that TBB and DMAT are also affecting the PI3K-related kinase family. It is not 
(A)

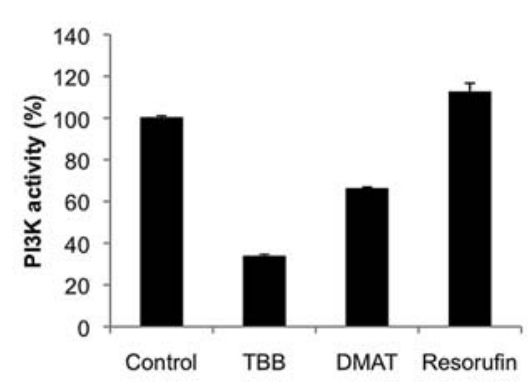

(B)

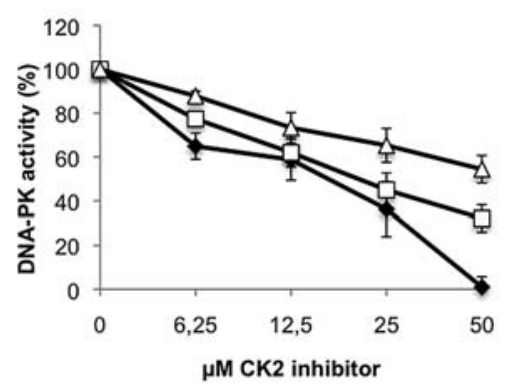

(C)

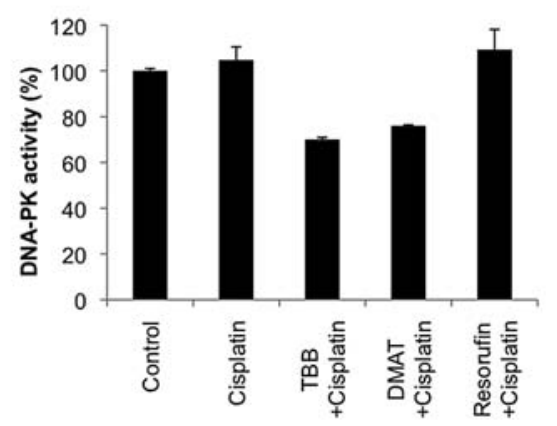

Figure 1. The CK2 inhibitors TBB and DMAT also inhibit PI3K and the PI3K-related kinase DNA-PK. (A) Luminometric kinase test with PI3K and the CK2 inhibitors TBB, DMAT and resorufin. The activity in the absence of inhibitors was set to $100 \%$. (B) The activity of DNA-PK was measured in lysates from MDA-MB-231 cells in the presence of increasing concentrations of TBB $(\bullet)$, DMAT $(\square)$ or resorufin $(\triangle)$. The activity of DNA-PK in the absence of inhibitors was set to $100 \%$. (C) MDA-MB-231 cells were incubated with $50 \mu \mathrm{M}$ TBB or resorufin and $25 \mu \mathrm{M}$ DMAT for $16 \mathrm{~h}$ before the addition of cisplatin $(50 \mu \mathrm{M})$ for an additional $8 \mathrm{~h}$. The activity of DNAPK was tested against the synthetic peptide PESQEAFADLWKK.

unlikely that these compounds might interfere with the catalytic subunit of DNA-dependent protein kinase (DNAPK), which like ATM (ataxia teleangiectasia-mutated protein) and ATR (ATM and Rad3-related), belong to the PI3K family of protein kinases. Hence, we tested DNA-PK activity in cellular MDA-MB-231 lysates in the presence of increasing concentrations of TBB, DMAT and resorufin (Fig. 1B). The results show that TBB inhibits DNA-PK activity significantly, whereas resorufin showed only a modest inhibition, especially at higher inhibitor concentrations; again the inhibition by DMAT is intermediate.

The results are further strengthened by experiments, where intact MDA-MB-231 cells were challenged with the three

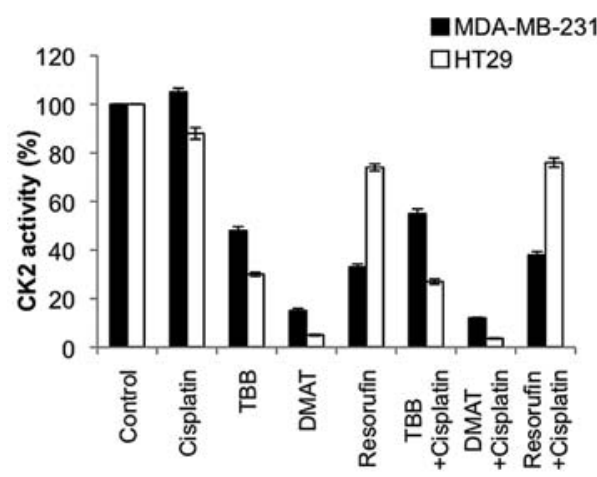

Figure 2. Inhibition of endogenous CK2 by TBB, DMAT and resorufin Human breast carcinoma MDA-MB-231 cells and human colorectal carcinoma HT29 cells were pre-incubated with $50 \mu \mathrm{M}$ TBB or resorufin or $25 \mu \mathrm{M}$ DMAT. After $16 \mathrm{~h}$ cisplatin was added to a final concentration of $50 \mu \mathrm{M}$ for an additional $8 \mathrm{~h}$. CK2 kinase activity in cell lysates was determined against the synthetic peptide RRRADDSDDDDD.

CK2 inhibitors as shown in Fig. 1C. DNA-PK is activated by DNA breaks (30), hence, MDA-MB-231 cells were incubated with the DNA-damaging drug cisplatin alone or in combination with the three inhibitors. Whereas cisplatin treatment did not show any effect on DNA-PK activity (probably because the measured activity of DNA-PK represents the amount of DNA-PK that can be activated by exogenous DNA, but not the amount of DNA-PK that is actually active in the cells), TBB and DMAT caused a reduction by 40 and 30\%, respectively. Resorufin did not affect DNA-PK activity at all (Fig. 1C).

Inhibition of endogenous $C K 2$. We also measured endogenous CK2 activity in MDA-MB-231 and HT29 cell lines in the absence and presence of cisplatin (Fig. 2). Treatment with cisplatin alone did not have any effect on endogenous CK2 activity. However, treatment together with TBB led to a reduction of CK2 activity in the case of the MDA-MB-231 and HT2 2 cell lines by 50 and 70\%, respectively; yet treatment with DMAT led to a reduction of 90 and $95 \%$, respectively. Resorufin treatment reduced CK2 activity in the case of the HT2 2 cells by $25 \%$ and in the case of the MDA-MB-231 cells by ca. $70 \%$. Co-treatment with cisplatin did not lead to a further decrease of CK2 activity (Fig. 2). Hence, the most potent inhibition of endogenous CK2 activity was obtained by DMAT. These results again show that the efficiency of the inhibitors is strongly cell type-specific, as has been described previously (27). CK2 activity measured in HT29 cells was approximately twice as high as in MDA-MB-231 cells.

Monitoring the activation of stress kinases upon cisplatin treatment. It is believed that one of the major components in deciding cell fate in response to cisplatin are the stressactivated protein kinases (reviewed in ref. 31) and it has previously been shown that DNA-dependent protein kinase (DNA-PK) is required for the late-activation of JNK (Jun-Nterminal kinase) upon genotoxic stress using the alkylating agent methyl methanesulfonate (MMS) (32). Since TBB and to a lesser degree DMAT, in contrast to resorufin, inhibited besides CK2 also DNA-PK, we next analysed cisplatininduced stress signaling by monitoring the phosphorylation of JNK and p38. 


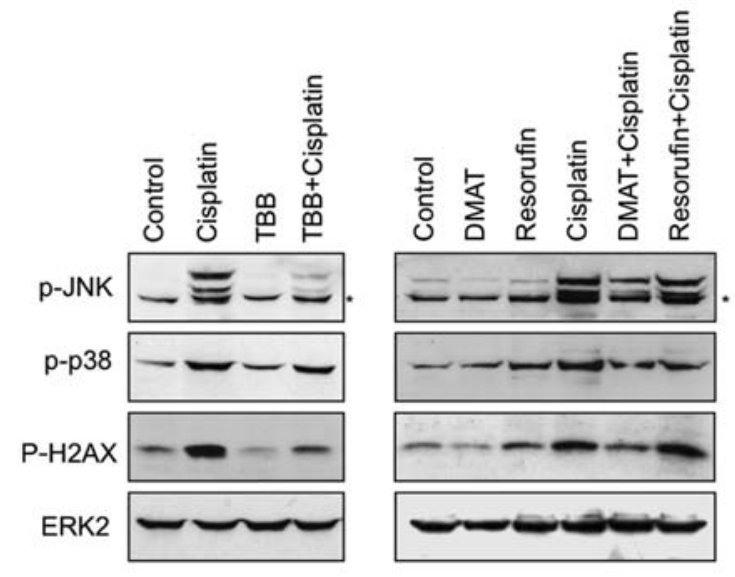

Figure 3. Effect of CK2 inhibitors on the cisplatin-induced phosphorylation of the stress kinases JNK1/2, p38 and histone H2AX. Western blot analysis of breast carcinoma MDA-MB-231 cells pre-incubated with $50 \mu \mathrm{M}$ TBB or resorufin or $25 \mu \mathrm{M}$ DMAT. After $16 \mathrm{~h}$ cisplatin was added to a final concentration of $50 \mu \mathrm{M}$ for an additional $8 \mathrm{~h}$. As internal protein loading control, ERK2 protein expression was used.

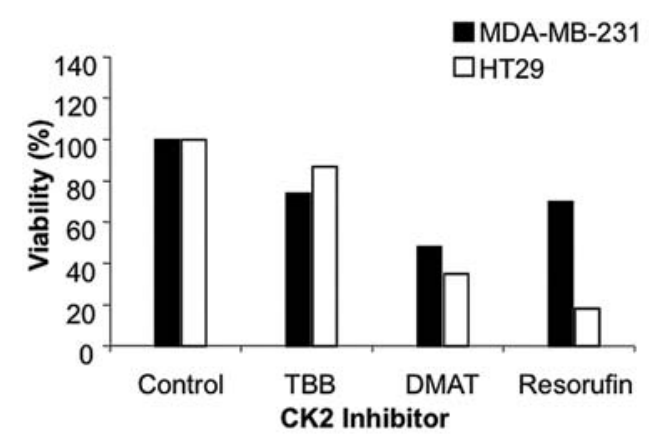

Figure 4. Effect of the CK2 inhibitors (TBB, DMAT and resorufin) on cell viability in human breast adenocarcinoma MDA-MB-231 cells and human colorectal adenocarcinoma HT29 cells. Cells were pre-incubated with $50 \mu \mathrm{M}$ TBB or resorufin or $25 \mu \mathrm{M}$ DMAT for 5 and then $72 \mathrm{~h}$ using $50 \%$ of the pre-treatment dose. At the end of incubation viability was determined using the WST-1 assay.

MDA-MB-231 cells were incubated for $24 \mathrm{~h}$ with TBB, DMAT or resorufin; for the last $8 \mathrm{~h}$ cisplatin was added to a final concentration of $50 \mu \mathrm{M}$. Activation of the stress kinases (JNK and p38) was monitored by Western blot analysis using phosphospecific antibodies. Treatment of cells with cisplatin led to phosphorylation of JNK and p38, in agreement with published data (31). H2AX was also included to monitor DNA-damage-related histone phosphorylation at S139 $(33,34)$, since it is phosphorylated in response to cisplatin and has been found to be a substrate for DNA-PK upon DNA-damage $(35,36)$.

Treatment with TBB or DMAT alone has no effect on the phosphorylation status of P-JNK and P-p38, but slightly decreases the phosphorylation of H2AX. Treatment with TBB together with cisplatin (Fig. 3, lane 4), however, shows an attenuation of the phosphorylation of JNK and H2AX. The inhibitory effect of TBB is specific for JNK and H2AX, as it was not observed for p38. DMAT also partially attenuated cisplatin-induced phosphorylation of JNK and H2AX, whereas resorufin did not. The slight increase in phosphorylation of
(A)
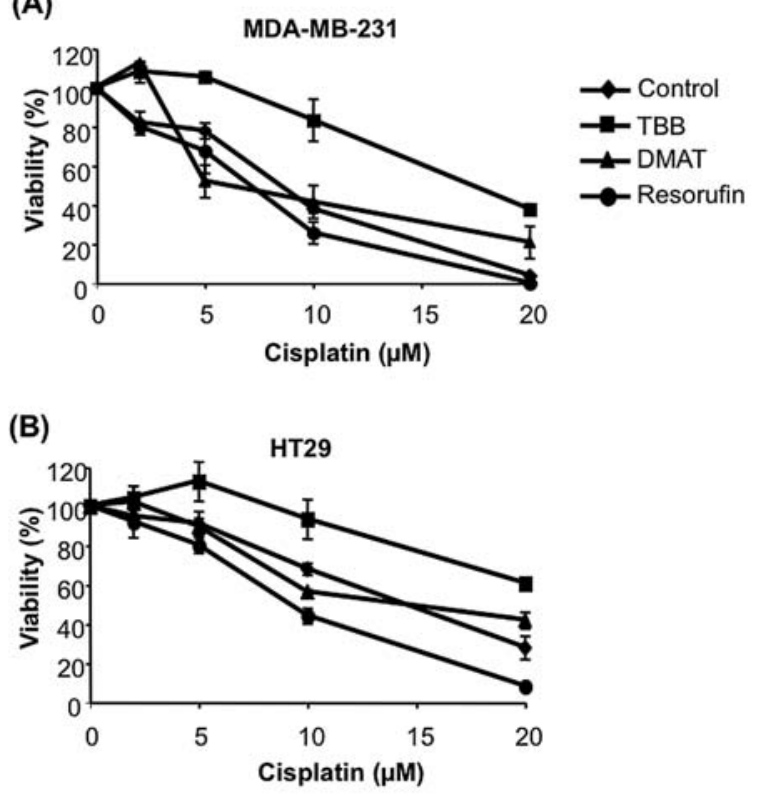

Figure 5. Effect of the combination of CK2 inhibitors and cisplatin on cell viability. Cells were pretreated with $50 \mu \mathrm{M}$ TBB or resorufin or $25 \mu \mathrm{M}$ DMAT [or no inhibitor (control)], followed by incubation with different concentrations of cisplatin and $50 \%$ of the pre-treatment dose of CK2 inhibitors. After $72 \mathrm{~h}$, cell viability was measured using the WST-1 assay. Viability was set to $100 \%$ for samples only treated with the inhibitor.

H2AX by resorufin alone could be explained by the observation that slightly more protein was loaded in this lane, since also intensity of the unspecific band detected by the PJNK antibody is increased.

There is no correlation between inhibition of CK2 in MDA-MB-231 cells using the different inhibitors (Fig. 2) and the observed decreased phosphorylation of H2AX and JNK. However, there is a good correlation between inhibition of DNA-PK (Fig. 1) and the attenuated phosphorylation of the stress kinase JNK and histone H2AX (Fig. 3). TBB was the most effective and resorufin the least effective, DMAT showed an intermediate inhibitory status both with respect to attenuation of phosphorylation and also to inhibition of DNA-PK.

CK2 inhibitors affect cell viability. To examine the response of the different CK2 inhibitors (TBB, DMAT and resorufin) on cell viability of the human tumor cell lines, MDA-MB231 and HT29. The cells were pretreated with $50 \mu \mathrm{M}$ TBB or resorufin or $25 \mu \mathrm{M}$ DMAT for $5 \mathrm{~h}$ followed by incubation with $50 \%$ of the pretreatment dosage. After $72 \mathrm{~h}$, cell viability was measured using the WST-1 assay [although resorufin in its oxidized form is used in colorimetric bioassays, there was no interference with the WST-assay (results not shown)]. Fig. 4 shows that TBB treatment affected the viability of the cell lines maximally at 25\%. DMAT treatment impaired cell viability of MDA-MB-231 and HT29 cells by 50 and 60\%, respectively.

Resorufin treatment affected the cell line MDA-MB-231 at $\sim 30 \%$. However, in the case of the HT29 the effect on cell viability was $80 \%$, supporting the notion that the effects of TBB, DMAT and resorufin on cell viability are dependent on the cell lines used. 
Cisplatin-induced cytotoxicity in the presence of $C K 2$ inhibitors. Next we investigated the effect of the CK2 inhibitors on the viability of the two cell lines in the presence of increasing concentrations of the anti-cancer drug cisplatin (Fig. 5). The cells were again pretreated with $50 \mu \mathrm{M}$ TBB or resorufin or $25 \mu \mathrm{M}$ DMAT, followed by increasing concentrations of cisplatin and $50 \%$ of the pretreatment dosage of the CK2 inhibitors. After $72 \mathrm{~h}$, cell viability was measured using the WST-1 assay. The CK2 inhibitors affected viability to different degrees (Fig. 4). The starting point (100\%) is viability only after treatment with the inhibitor.

Cisplatin treatment in the absence of CK2 inhibitors (control) affected cell viability of both cell lines investigated (Figs. 5A and B). In the case of the MDA-MB-231 and HT29 cells $10 \mu \mathrm{M}$ cisplatin treatment alone led to a reduction of cell viability by 60 and $30 \%$, respectively. Co-treatment with TBB seemed to have a 'rescuing' effect in both cell lines. Resorufin in the presence of $10 \mu \mathrm{M}$ cisplatin, caused attenuation of cell viability in the case of MDA-MB-231 and HT29 cells by 70 and $50 \%$, respectively (Fig. 5). DMAT-treated cells, when challenged with $10 \mu \mathrm{M}$ cisplatin differed only slightly in cell viability from resorufin-treated cells. The results demonstrate that there is a strong dependency of the inhibitor effect depending on the cell lines used and that the cell lines exhibit different cellular viability in response to the different inhibitors when used in combination with cisplatin.

\section{Discussion}

In search for the 'magic bullet', for better and more effective disease therapies, industry and academia are currently screening for compounds interfering with impaired signaling pathways, thereby, especially, focusing on protein kinases. Protein kinases belong to the second largest family of enzymes and have in common a rather conserved ATPbinding domain. Hence, it does not come as a surprise that most of the compounds found to interfere with kinase activities are targeting this site (class I inhibitors). Despite the remarkable potency of some inhibitors, one of the pitfalls of these inhibitors is that they target not only one specific kinase but also a whole spectrum of others. Monitoring these compounds with scrutiny in vitro and in vivo should therefore be mandatory. Although the panel of recombinant protein kinases for specificity screening of potential kinase inhibitors is steadily increasing, protein kinases such as ATM/ATR, DNA-PK and others are still unavailable as recombinant proteins and hence, escape routine testing with respect to being potentially targets of many kinase inhibitors applied.

Here, we have investigated the effect of three established protein kinase CK2 inhibitors, i.e. TBB, DMAT and resorufin by testing their influence on PI3K, DNA-PK and CK2 activity and activation of stress kinases, e.g. JNK, p38 after induction of DNA damage by the anti-cancer drug cisplatin. In addition, we have tested the effects on cell viability in combination with cisplatin.

Cell viability investigations revealed that these compounds challenged the two investigated cell lines to different degrees (Figs. 4 and 5). TBB had the least effect on cell viability in both cell lines and resorufin exerted the strongest effect. These results support the notion that the choice of cell lines for particular in vivo investigations with respect to the effect of potential kinase inhibitors should not be underestimated. Hence, the NIH 60 cell line test is a very reasonable approach to monitor, in a first attempt, the efficiency of a potential compound candidate, since there are large differences with respect to drug and the cell line used (37).

Endogenous protein kinase CK2 activity is affected by the three compounds. DMAT proves to be the most effective compound interfering with $\mathrm{CK} 2$ activity, irrespective of which cell line was used. In the case of TBB and resorufin, inhibition of endogenous CK2 activity varies considerably between HT29 and MDA-MB-231 cells. Yet, for all three compounds no direct correlation between endogenous CK2 inhibition and cell viability can be established, supporting the notion that beside CK2, other molecules involved in cell survival, are targeted by TBB, DMAT and resorufin.

Additionally, we investigated the effect of the CK2 inhibitors on the activity of the kinases PI3K and DNA-PK. Although a limited primary sequence homology between PI3K and DNA-PK exists, the two are coined pharmacological homologs since PI3K inhibitors usually also target DNA-PK (38), which is also supported by our results. TBB inhibited both PI3K and DNA-PK, whereas resorufin only marginally affected DNA-PK and PI3K. DMAT showed an intermediate behavior.

We have also inspected the effect of the three CK2 inhibitors in the absence and presence of the anti-cancer drug cisplatin. DNA-damaging agents induce DNA damage response (DDR) involving activation of DNA-repair mechanisms and cell-cycle 'checkpoint' signaling (39). As a consequence of the formation of DNA lesions, in particular DNA double-strand breaks (DSB), ATM, ATR and DNA$\mathrm{PK}$, which are PI3K-related kinases (PIKKs), are activated and phosphorylate $\mathrm{H} 2 \mathrm{AX}$ as well as many other DNA-repair and checkpoint proteins $(36,40,41)$. Late-activation of stress kinases (JNK, p38) by the genotoxin MMS requires the DNA-repair protein DNA-PK and CSB (32). Furthermore, inhibition of PI3-kinases by low dose of wortmannin is known to attenuate activation of JNK by genotoxic stress (42). Hence, in order to exclude interference between the CK2 inhibitors TBB, DMAT and resorufin with class I PI3K and the PI3K-related kinase family member DNA-PK, which so far has not been tested in vitro with these inhibitors, we have monitored the phosphorylation of H2AX, p38 and JNK.

These analyses revealed that TBB and DMAT, but not resorufin, were able to attenuate cisplatin-induced signaling to JNK and H2AX. Interestingly, inhibition of cisplatintriggered stress response by TBB and DMAT coincides with the inhibition of PI3K ( $\alpha$-subunits) and DNA-PK. These results are especially interesting in the light of recent reports of protein kinase CK2 phosphorylation of MDC1, a protein that has been shown to interact with several DDR proteins, including the MRE11-RAD50-NBS1 (MRN) complex $(40,41,43,44)$. In these studies protein kinase CK2 inhibitors (e.g. DMAT and TBB) and CK2 down-regulation experiments by siRNA were used to demonstrate a role for CK2 in the phosphorylation of MDC1. Protein kinase CK2 has been shown to facilitate repair of chromosomal DNA single-strand breaks (45). However, great care should be taken when using 'so-called highly specific CK2 inhibitors' such as TBB, and 
assigning a role for CK2 in an orchestra of molecules involving pleiotropic PI3K-related kinases and their downstream substrates.

In conclusion, apart from CK2, TBB and DMAT inhibit additional protein kinases, including the DNA damage sensoring and repair protein DNA-PK, thereby having impact on stress signaling and cell death induced by the anti-cancer drug cisplatin.

\section{Acknowledgements}

We appreciate the competent and excellent work of Tine Rasmussen and Mia S. Andersen. This work was supported by a grant from the Danish Cancer Society to BBO (DP06083), by grants to OGI from the Danish Cancer Society (DP07109) and from NOVO NORDISK FONDEN and by a grant from the Deutsche Forschungsgemeinschaft to GF (DFG; FR 1241/5-3).

\section{References}

1. Niefind K, Guerra B, Pinna LA, Issinger OG and Schomburg D: Crystal structure of the catalytic subunit of protein kinase CK2 from Zea Mays at 2.1 A resolution. EMBO J 17: 2451-2462, 1998.

2. Niefind K, Guerra B, Ermakowa I and Issinger OG: Crystal structure of human protein kinase CK2: insights into basic properties of the CK2 holoenzyme. EMBO J 20: 5320-5331, 2001

3. Chantalat L, Leroy D, Filhol O, et al: Crystal structure of the human protein kinase CK2 regulatory subunit reveals its zinc finger mediated dimerization. EMBO J 18: 2930-2940, 1999.

4. Ermakowa I, Boldyreff B, Issinger OG and Niefind K: Crystal structure of a C-terminal deletion mutant of human protein kinase CK2 catalytic subunit. J Mol Biol 330: 925-934, 2003.

5. Raaf J, Brunstein E, Issinger OG and Niefind K: The interaction of CK2alpha and CK2beta, the subunits of protein kinase CK2, requires CK2beta in a preformed conformation and is enthalpically driven. Protein Sci 17: 2180-2186, 2008.

6 . Niefind $\mathrm{K}$ and Issinger OG: Targeting protein/protein interactions. Screening 1: 18-21, 2008.

7. Niefind K, Pütter M, Guerra B, Issinger OG and Schomburg D: GTP plus water mimic ATP in the active site of protein kinase CK2. Nat Struct Biol 6: 1100-1103, 1999.

8. Ahmed K, Gerber DA and Cochet C: Joining the cell survival squad: an emerging role for protein kinase CK2. Trends Cell Biol 12: 226-230, 2002.

9. Guerra B, Siemer S, Boldyreff B and Issinger OG: Protein kinase CK2: evidence for a protein kinase CK2beta subunit fraction, devoid of the catalytic alpha subunit, in mouse brain and testicles. FEBS Lett 462: 353-357, 1999.

10. Buchou T, Vernet M, Blond O, et al: Disruption of the regulatory beta subunit of protein kinase CK2 in mice leads to a cellautonomous defect and early embryonic lethality. Mol Cell Biol 23: 908-915, 2003

11. Lou DY, Dominguez I, Toselli P, Landesman-Bollag E, O'Brien C and Seldin DC: The alpha catalytic subunit of protein kinase CK2 is required for mouse embryonic development. Mol Cell Biol 28: 131-139, 2008

12. Xu X, Toselli PA, Russell LD and Seldin DC: Globozoospermia in mice lacking the casein kinase II alpha' catalytic subunit. Nat Genet 23: 118-121, 1999

13. Litchfield DW: Protein kinase CK2: structure, regulation and role in cellular decisions of life and death. Biochem J 369: 1-15, 2003.

14. Bibby AC and Litchfield DW: The multiple personalities of the regulatory subunit of protein kinase CK2: CK2 dependent and CK2 independent roles reveal a secret identity for CK2beta. Int J Biol Sci 1: 67-79, 2005 .

15. Olsen BB and Guerra B: Ability of CK2beta to selectively regulate protein kinases. Mol Cell Biochem 316: 115-126, 2008.

16. Guerra B and Issinger OG: Protein kinase CK2 in human diseases. Curr Med Chem 15: 1875-1886, 2008.

17. Sarno $S$ and Pinna LA: Protein kinase CK2 as a druggable target. Mol Biosyst 4: 889-894, 2008.
18. Pagano MA, Cesaro L, Meggio F and Pinna LA: Protein kinase CK2: a newcomer in the 'druggable kinome'. Biochem Soc Trans 34: 1303-1306, 2006.

19. Sarno S, Salvi M, Battistutta R, Zanotti G and Pinna LA: Features and potentials of ATP-site directed CK2 inhibitors. Biochim Biophys Acta 1754: 263-270, 2005

20. Nie Z, Perretta C, Erickson P, et al: Structure-based design, synthesis, and study of pyrazolo $(1,5-a)(1,3,5)$ triazine derivatives as potent inhibitors of protein kinase CK2. Bioorg Med Chem Lett 17: 4191-4195, 2007

21. Nie Z, Perretta C, Erickson P, et al: Structure-based design and synthesis of novel macrocyclic pyrazolo $(1,5-a)(1,3,5)$ triazine compounds as potent inhibitors of protein kinase CK2 and their anticancer activities. Bioorg Med Chem Lett 18: 619-623, 2008.

22. Persson T, Yde CW, Rasmussen JE, Rasmussen TL, Guerra B, Issinger OG and Nielsen J: Pyrazole carboxamides and carboxylic acids as protein kinase inhibitors in aberrant eukaryotic signal transduction: induction of growth arrest in MCF-7 cancer cells. Org Biomol Chem 5: 3963-3970, 2007.

23. Pagano MA, Andrzejewska M, Ruzzene M, et al: Optimization of protein kinase CK2 inhibitors derived from 4,5,6,7tetrabromobenzimidazole. J Med Chem 47: 6239-6247, 2004

24. Pagano MA, Meggio F, Ruzzene M, Andrzejewska M, Kazimierczuk Z and Pinna LA: 2-Dimethylamino-4,5,6,7tetrabromo-1H-benzimidazole: a novel powerful and selective inhibitor of protein kinase CK2. Biochem Biophys Res Commun 321: 1040-1044, 2004.

25. Olsen BB, Rasmussen T, Niefind K, and Issinger OG: Biochemical characterization of CK2alpha and alpha' paralogues and their derived holoenzymes: evidence for the existence of a heterotrimeric CK2alpha' -holoenzyme forming trimeric complexes. Mol Cell Biochem 316: 37-47, 2008.

26. Pagano MA, Bain J, Kazimierczuk Z, et al: The selectivity of inhibitors of protein kinase CK2. An update. Biochem J 415: 353-365, 2008.

27. Sandholt I, Olsen BB, Guerra B and Issinger OG: Resorufin, a lead for a new protein kinase CK2 inhibitor. Anticancer Drugs 20: 238-248, 2009.

28. Zhang J, Yang PL and Gray NS: Targeting cancer with small molecule kinase inhibitors. Nat Rev Cancer 9: 28-39, 2009.

29. Boldyreff B, Rasmussen T, Jensen HH, Cloutier A, Baudet L, Roby P and Issinger OG: Expression and purification of PI3 kinase alpha and development of an ATP depletion and an alphascreen PI3 kinase activity assay. J Biomol Screen 13: 1035-1040, 2008.

30. Achari Y and Lees-Miller SP: Detection of DNA-dependent protein kinase in extracts from human and rodent cells. In: Methods in Molecular Biology. Stress response: Methods and Protocols. Vol. 99. Keyse SM (ed.). Humana Press Inc., pp85-97, 2000.

31. Brozovic A and Osmak M: Activation of mitogen-activated protein kinases by cisplatin and their role in cisplatin-resistance. Cancer Lett 251: 1-16, 2007.

32. Fritz G and Kaina B: Late activation of stress kinases (SAPK/ JNK) by genotoxins requires the DNA repair proteins DNAPKc and CSB. Mol Cell Biol 17: 851-861, 2006.

33. Rogakou EP, Pilch DR, Orr AH, Ivanova VS and Bonner WM: DNA double-stranded breaks induce histone H2AX phosphorylation on serine 139. J Biol Chem 273: 5858-5868, 1998.

34. Sedelnikova OA, Pilch DR, Redon $\mathrm{C}$ and Bonner WM: Histone $\mathrm{H} 2 \mathrm{AX}$ in DNA damage and repair Cancer Biol Ther 2: 233-235, 2003.

35. Olive PL and Banáth JP: Kinetics of H2AX phosphorylation after exposure to cisplatin. Cytometry B Clin Cytom 76: 79-90, 2008.

36. Bonner WM, Redon CE, Dickey JS, Nakamura AJ, Sedelnikova OA, Solier S and Pommier Y: Gamma H2AX and cancer. Nat Rev Cancer 8: 957-967, 2008.

37. http://dtp.nci.nih.gov/dtpstandard/servlet/doseresponse?search type $=$ NSC \& searchlist $=12097$

38. Knight ZA, Gonzalez B, Feldman ME, et al: A pharmacological

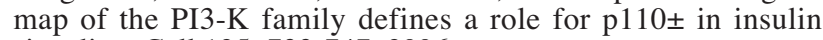
signaling. Cell 125: 733-747, 2006.

39. Kastan M and Bartek J: Cell-cycle checkpoints and cancer. Nature 432 316-323, 2004.

40. Spycher C, Miller ES, Townsend K, et al: Constitutive phosphorylation of MDC1 physically links the MRE11-RAD50NBS1 complex to DNA damage. J Cell Biol 181: 227-240, 2008. 
41. Chapman JR and Jackson SP: Phospho-dependent interactions between NBS1 and MDC1 mediate chromatin retention of the MRN complex at the sites of DNA damage. EMBO Rep 9: 795-801, 2008

42. Fritz G and Kaina B: Activation of c-jun N-terminal kinase 1 by UV irradiation is inhibited by wortmannin without affecting c-jun expression. Mol Cell Biol 19: 1768-1774, 1999.

43. Wu L, Luo K, Lou Z and Chen J: MDC1 regulates intra-S-phase checkpoint by targeting NBS1 to DNA double-strand breaks. Proc Natl Acad Sci USA 105: 11200-11206, 2008.
44. Melander F, Bekker-Jensen S, Falck J, Bartek J, Mailand N and Lukas J: Phosphorylation of SDT repeats in the MDC1 Nterminus triggers retention of NBS1 at the DNA damagemodified chromatin. J Cell Biol 181 213-226, 2008.

45. Loizou JL, El-Khamisy SF, Zlatanou A, et al: The protein kinase CK2 facilitates repair of chromosomal DNA singlestrand breaks. Cell 117: 17-28, 2004. 